\title{
KNOWLEDGE OF GOVERNMENT AND PRIVATE PRIMARY HEALTH CARE WORKERS ON NEWBORN CARE COMPONENTS: A QUESTIONNAIRE-BASED CROSS-SECTIONAL COMPARATIVE STUDY
}

\author{
PANDIAMUNIAN J ${ }^{1 *}$, ISHWARYA T ${ }^{2}$ \\ ${ }^{1}$ Department of Pharmacology, Vinayaka Mission's Medical College and Hospital, Karaikal, Puducherry, India. ${ }^{2}$ Consultant Paediatrician, \\ Leonard Hospital, Batlagundu, Dindigul, Tamil Nadu, India. Email: jpandiamunian@gmail.com
}

Received: 18 November 2016, Revised and Accepted: 25 November 2016

ABSTRACT

Objective: This study was done to evaluate the knowledge of primary health-care workers about the newborn care components.

Methods: The Institutional Ethics Committee approval was obtained, and a cross-sectional study was carried out among the primary health-care workers of Karaikal using a pretested questionnaire from January 2015 to March 2015. The questionnaire contained questions on various domains of newborn care components. The study participants were explained about the study. Verbal informed consent was obtained, and the questionnaire was introduced to 383 health-care workers. The answered questionnaires were collected and analyzed.

Results: A total of 349 participants (192-government employees; 157-private employees) were willing to take part in the study. Most (54.7\%) of the government participants were nurses and auxiliary nurse midwives (43.2\%) whereas the private sector participants were predominantly (79\%) nurses. The knowledge level about some of the newborn care components, namely, positioning and attachment, advice on discharge, time of follow-up checkup, bad child rearing practices, and danger signs of newborn were assessed to be predominantly inadequate among a majority of health workers of both sectors. $22.29 \%$ and $41.1 \%$ of the private health-care workers and government health-care workers respectively, were having an overall adequate knowledge (overall score $>75 \%$ ) on newborn care components. Knowledge of the government health workers was significantly better than private health-care $\operatorname{staff}(P<0.001)$.

Conclusion: Knowledge is found to be inadequate among health-care workers on some newborn care components which necessitate measures to improve.

Keywords: Newborn care, Nurses, Midwives, Inadequate knowledge, Training programs.

(C) 2016 The Authors. Published by Innovare Academic Sciences Pvt Ltd. This is an open access article under the CC BY license (http://creativecommons. org/licenses/by/4. 0/) DOI: http://dx.doi.org/10.22159/ajpcr.2016.v10i3.16219

\section{INTRODUCTION}

Provision of good essential newborn care to the neonates will result in a reduction in the neonatal mortality rate in the country [1]. The neonatal mortality depends on the knowledge of the health-care workers in newborn care as well as on the utilization of health facilities by the mother [2]. The global agenda for newborn health published in the Lancet series concluded that it is possible to reduce neonatal mortality by improved knowledge and skills among health-care workers [3]. In India, a high level of knowledge among community health workers is considered to be crucial for improving coverage and adherence to recommended newborn care practices [4]. Hence, this study was done to evaluate the knowledge about the essential newborn care components among the health-care providers (excluding doctors) employed in various health-care sectors of Karaikal District (Puducherry Union Territory, South India) and also to compare the level of the knowledge between the government and private health-care workers of the region.

\section{METHODS}

Approval for conducting the study was obtained from the Institutional Ethics Committee. Waiver for written informed consent was obtained from the Ethics Committee as the study did not involve any intervention to any of the study participant. Permissions were obtained from the heads of all the health-care sectors involved in the study for administering the questionnaire to their employees and conducting the study among their employees. Verbal informed consent was obtained from the participants to take part in the study after being explained about the study. The study was carried out over a period of 3 months from January 2015 to March 2015 in all the health sectors of Karaikal. Karaikal is a port city in the east coast of India and a municipality in Karaikal district in the Union Territory of Puducherry with a population of around 2 lakhs. There are a private medical college, a government general hospital, two nursing homes, one community health center, 11 primary health centers and 17 sub-centers providing health care services in Karaikal. The study involved the primary health workers including the nurses, midwives, health assistants, and health visitors employed in all the health sectors of Karaikal. Doctors were not involved in the study.

In the absence of reference data, prevalence of adequate knowledge among health workers was assumed to be $50 \%$, and the sample size was estimated as follows,

- Hypothesized \% frequency of outcome factor in the population (p): $50 \%$

- Confidence limits as \% of 100 (absolute $\pm \%$ ) (l): $5 \%$

- $\mathrm{Z}_{1-\alpha / 2}$ value for $95 \%$ confidence interval: 1.96

- $\quad$ Sample size $\mathrm{N}=4 \mathrm{pq} / \mathrm{d}^{2}=384$.

Demographic details such as age, gender, professional qualification, job location, working experience (in years) of the study participants were collected. A questionnaire was prepared for the study with 28 questions on 12 different newborn care components as shown in Table 1.

The questionnaire was pilot tested and validated. The questionnaire contained only the questions and blank spaces for answers to be written 
by the participants to avoid the bias of selecting the correct option by chance with multiple choice questions. Answer key was prepared for the questions. Questionnaires were given to the health-care workers who were found to be present on duty. Answered questionnaires were immediately retrieved by the investigator after they were being completed by the participants. All the answered questionnaires were collected and evaluated by the same investigator. The marks obtained in each domain were converted to percentage of correct answers for that domain.

The knowledge of the participant for a particular component was considered adequate if the score for the component was $>75 \%$; moderate if the score was between $50 \%$ and $75 \%$ and inadequate if it was $<50 \%$.

A comparison of overall newborn care knowledge level between the government and private sector workers was done. This was assessed based on the total number of questions answered correctly out of the 28 questions on all the newborn care components asked in the questionnaire. This overall comparison of knowledge level between the two groups of participants was done using the Mann-Whitney test.

\section{RESULTS}

The primary health-care providers, excluding doctors who were enrolled in the region to provide essential newborn care and followup care for the newborn babies, included the Nurses; auxiliary nurse midwives (ANMs), general nurse midwives, female health visitors, and nursing assistants.

Among the 384 health-care workers of Karaikal who were explained about the study, 349 were willing to take part in the study. Among the 349 study participants, 192 were government employees and 157 were working in various private health-care facilities. All the study participants were females. The years of working experience of government health workers were ranging between 1 year and 36 years and the mean ( \pm standard deviation [SD]) years of experience of them was found to be $5.7786( \pm 5.199)$ years. The years of working experience of 157 private health workers were ranging between 0.5 years and 10 years and the mean $( \pm S D)$ years of experience of them was found to be $3.5806( \pm 1.809)$ years.

The distribution of government and private health workers as per their employment category is as given in Table 2. Most of the (54.7\%) government participants were nurses and ANMs (43.2\%) whereas the private sector participants were predominantly nurses (79\%).

Table 3 shows the distribution of the workplaces of the study participants. The majority (57.3\%) of the government participants were employed in the government general hospital of the region while those employed in the private nursing homes formed a major portion (56.1\%) for the private sector participants.

Table 4 shows the level of knowledge of government and private sector health-care workers about the newborn care components. Knowledge on the components $1,3,4,9$, and 12 were found predominantly to be in the moderate to adequate range among the government health workers, while the knowledge level about the components 2, 5, 7, 8, 10, and 11 were assessed to be predominantly inadequate among majority of the government sector participants.

The majority of the private health-care workers were found to be having moderate to adequate knowledge about the components $1,3,4$, 9 , and 12 while major proportion of them were lacking knowledge on the components $2,5,6,7,8,10$, and 11 .

Fig. 1 shows the overall comparison of newborn care knowledge level between the government and private sector workers. It was noticed
Table 1: Number of questions in the questionnaire on various newborn care components

\begin{tabular}{lll}
\hline S. No. & New born care component & $\begin{array}{l}\text { Question } \\
\text { numbers in the } \\
\text { questionnaire }\end{array}$ \\
\hline 1 & Umbilical cord care & $1-3$ \\
2 & Bath to newborn & $4-7$ \\
3 & Warmth and attachment & $8-11$ \\
4 & Breastfeeding & $12-16$ \\
5 & Positioning & 17 \\
6 & Vaccination at birth & 18,19 \\
7 & Discharge advice & 20 \\
8 & Time of follow-up check up & 21 \\
9 & Contraception method in the & $22-24$ \\
& postpartum period & \\
10 & Bad child rearing practices & 25 \\
11 & Danger signs of newborn & 26 \\
12 & Health and personal hygiene advices & 27,28 \\
\hline
\end{tabular}

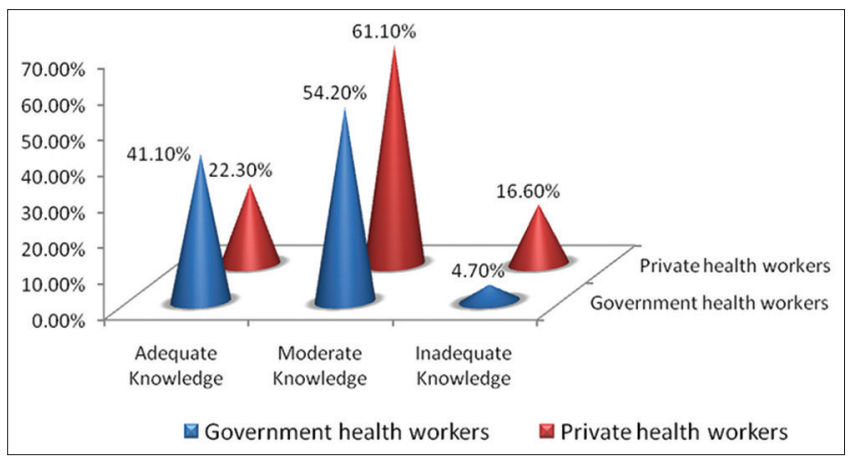

Fig. 1: Comparison of overall knowledge level between the government and private sector health workers

that $95.3 \%$ of the government health workers were having moderate $(54.2 \%)$ to adequate $(41.10 \%)$ knowledge compared to $83.4 \%$ of the private health workers having moderate $(61.10 \%)$ to adequate $(22.3 \%)$ knowledge. Knowledge of the government health-care workers was found to be significantly $(P<0.005)$ better than the private health-care participants.

\section{DISCUSSION}

This study was done to evaluate the level of knowledge of primary health-care workers in newborn care components and also to compare the knowledge level between government and private sector workers. It was observed in the study that the average duration of experience of government health worker participants was higher (5.7786 \pm 5.199 years) compared to that of the private sector workers $(3.5806$ \pm 1.809 years). Nurses and midwives were the predominant primary health-care workers in the region.

It was also found in the current study that the majority of the healthcare workers of Karaikal had a moderate to adequate (50-100\%) knowledge toward the umbilical cord care. However, nearly, one-third of the participants from both the sectors had inadequate knowledge about this component. Another Indian study done in Meerut, Haryana by Sinha et al. also reported that the knowledge and skills of health workers were moderate regarding the umbilical cord care [5]. Various studies done worldwide among the postnatal mothers reported the use of some unsafe materials on the newborn's umbilical cord [6-8]. These findings necessitate the presence of trained health-care workers in home-based normal vaginal deliveries, and the health workers who lack adequate knowledge need to be given sufficient training and education to prevent complications due to improper umbilical cord care. 
Table 2: Distribution of the health worker participants based on their employment category

\begin{tabular}{|c|c|c|c|c|c|}
\hline \multicolumn{3}{|l|}{ Government health workers } & \multicolumn{3}{|l|}{ Private health workers } \\
\hline Category of health worker & $\begin{array}{l}\text { Number of } \\
\text { participants }\end{array}$ & $\begin{array}{l}\text { Percentage of } \\
\text { participants }\end{array}$ & Category of health worker & $\begin{array}{l}\text { Number of } \\
\text { participants }\end{array}$ & $\begin{array}{l}\text { Percentage of } \\
\text { participant }\end{array}$ \\
\hline Nurse & 105 & 54.7 & Nurse & 124 & 79 \\
\hline ANM & 83 & 43.2 & Nursing assistant & 20 & 12.7 \\
\hline GNM & 1 & 0.5 & ANM & 12 & 7.6 \\
\hline LHV & 3 & 1.6 & GNM & 1 & 0.6 \\
\hline Total & 192 & 100 & Total & 157 & 100 \\
\hline
\end{tabular}

ANM: Auxiliary nursing midwifery, GNM: General nursing and midwifery, LHV: Lady health visitor

Table 3: Distribution of study participants based on their job locations

\begin{tabular}{|c|c|c|c|c|c|}
\hline \multicolumn{3}{|l|}{ Government health workers } & \multicolumn{3}{|l|}{ Private health workers } \\
\hline Job location & $\begin{array}{l}\text { Number of } \\
\text { participants }\end{array}$ & $\begin{array}{l}\text { Percentage of } \\
\text { participants }\end{array}$ & Job location & $\begin{array}{l}\text { Number of } \\
\text { participants }\end{array}$ & $\begin{array}{l}\text { Percentage of } \\
\text { participants }\end{array}$ \\
\hline Government general hospital & 110 & 57.3 & Private nursing homes & 88 & 56.1 \\
\hline Primary health centres & 53 & 27.6 & Private medical college & 69 & 43.9 \\
\hline Community health centres & 29 & 15.1 & Total & 157 & 100 \\
\hline Total & 192 & 100 & & & \\
\hline
\end{tabular}

Table 4: Distribution of the government and private sector participants based on their knowledge level about newborn care components

\begin{tabular}{|c|c|c|c|c|c|c|}
\hline \multirow[t]{3}{*}{ Knowledge assessment parameters } & \multicolumn{6}{|c|}{ Knowledge level among the participants } \\
\hline & \multicolumn{2}{|l|}{ Adequate } & \multicolumn{2}{|l|}{ Moderate } & \multicolumn{2}{|c|}{ Inadequate } \\
\hline & G - n (\%) & P - n (\%) & G - n (\%) & $P-n(\%)$ & G - n (\%) & $P-\mathbf{n}(\%)$ \\
\hline Umbilical cord care & $55(28.6)$ & $40(25.5)$ & $73(38)$ & $61(38.9)$ & $64(33.3)$ & $56(35.7)$ \\
\hline Bath to new born & $16(8.3)$ & $9(5.7)$ & $43(22.4)$ & $13(8.3)$ & $133(69.3)$ & $135(86)$ \\
\hline Warmth and attachment & $92(47.9)$ & $59(37.6)$ & $77(40.1)$ & $48(30.6)$ & $23(12)$ & $50(31.8)$ \\
\hline Breast feeding & $146(76)$ & $108(68.8)$ & 39 (20.3) & $21(13.4)$ & $7(3.6)$ & $28(17.8)$ \\
\hline Positioning & $0(0)$ & $0(0)$ & $0(0)$ & $0(0)$ & $192(100)$ & $157(100)$ \\
\hline Vaccination at birth & $94(49)$ & $44(28)$ & $0(0)$ & $0(0)$ & $98(51)$ & $113(72)$ \\
\hline Discharge advice & $0(0)$ & $0(0)$ & $0(0)$ & $0(0)$ & $192(100)$ & $157(100)$ \\
\hline Time of follow-up check up & $0(0)$ & $0(0)$ & $0(0)$ & $0(0)$ & $192(100)$ & $157(100)$ \\
\hline Contraception method & $95(49.5)$ & $61(38.9)$ & 65 (33.9) & $53(33.8)$ & $32(16.7)$ & $43(27.4)$ \\
\hline Bad child rearing practices & $0(0)$ & $0(0)$ & $0(0)$ & $0(0)$ & $192(100)$ & $157(100)$ \\
\hline Danger signs of new born & $0(0)$ & $0(0)$ & $0(0)$ & $0(0)$ & $192(100)$ & $157(100)$ \\
\hline Health and personal hygiene advices & $169(88)$ & $150(95.5)$ & $0(0)$ & $0(0)$ & $23(12)$ & $7(4.5)$ \\
\hline
\end{tabular}

G: Government sector participants, P: Private sector participants, n: Number of participants

The knowledge on bath to newborn was predominantly inadequate among $69.3 \%$ government staff and $86 \%$ private staff. Bathing the newborn babies shortly after birth may increase the risk of hypothermia [9]. This finding of the present study correlates with results of another study done in an urban area of New Delhi where it was observed that bathing the baby immediately after birth was common practice in $82.6 \%$ of home deliveries [10]. Hence, this is an area of concern to be addressed among the Indian health-care professionals. The knowledge level on warmth to newborn was found to be moderate to adequate among the staff of both private and government health sectors.

It was noticed in this present study that $76 \%$ of the government participants and $68.8 \%$ of the private participants were having adequate knowledge on good breastfeeding practices. However, the remaining had moderate to inadequate knowledge which needs to be addressed. The knowledge about positioning was found to be inadequate among all the health workers of Karaikal in this study. Breast milk provides the ideal nutrition for infants and prevents many diseases in them. Lack of knowledge, non-supportive behaviors, attitude of maternity nurses, inconsistent advice, and minimal prenatal encouragement to breastfeed are barriers to good breastfeeding practice. The key to successful breastfeeding is information, education, and communication strategies aimed at behavior change. For such a promotional campaign to be effective, attitudes and practices of health-care providers must be improved [11,12]. Health professionals should be able to help a mother to do it right, especially when the mother is inexperienced or lacks experienced support at home. This is possible only with improved and adequate knowledge among the health workers.

Regarding the vaccination component, $49 \%$ of the government staff had adequate information and $51 \%$ had inadequate knowledge. Only $28 \%$ of the private sector health worker had a definite idea in this component and rest of them were found to be having inadequate knowledge. This shows that the knowledge of government healthcare workers is better than the private workers about the vaccination at birth. It was concluded in a study done in Bijapur city that the main reason for partial as well as non-immunization was a lack of information among health workers and lack of motivation to the mother [13]. The motivation to vaccinate the children needs to be spread primarily through the health workers. Hence, the health-care professionals' knowledge about the vaccines and the vaccination schedule need to be improved across the country.

This study finding estimated that the majority of the health-care staff of Karaikal have moderate to adequate knowledge on advice regarding contraception methods to the postnatal mothers. 
A great inadequacy of health workers' (100\% of participants) knowledge regarding the following components: Discharge advice to the mothers, bad child rearing practices, danger signs of the newborn, and the time of follow-up visit of babies (depending upon - Normal weight, low birth weight, and sick neonates) was observed. The study done in urban area of New Delhi found that bad child rearing practices were followed in that part of the country [10]. In accordance with the present study finding that the health-care workers lack knowledge on danger signs of newborn, a study done by Awasthi et al. in North India, identified that health-care providers could recognize some, but not all, the danger signs in pregnancy as well as in the neonate [14]. If the mothers are informed about the danger signs of the newborn, it will promote timely management of the illnesses and prevent neonatal mortality after home-based deliveries. The health workers are to provide knowledge to the mothers about the danger signs of newborn. However, if the health workers have inadequate knowledge, it will be reflected as an increased chance of sick babies likely to be presented late to the health facility, usually in critical conditions, therefore, increasing the chances of dying from preventable causes.

The study participants were found not to be aware of the optimal period for postnatal follow-up check-ups for both mother and newborn. The first postnatal check-up is expected to occur within the first 3 days of birth since this is considered the most dangerous time for newborn babies. Thus, there is an urgent need to reorient health-care providers about the ideal time for postnatal checkup.

Knowledge on health and personal hygiene advice to mothers at the time of discharge was appreciably found to be adequate among $88 \%$ of the government staff and $95.5 \%$ of the private staff.

By considering all the newborn care components together, it was found that $41.1 \%$ of Government health worker participants and $22.3 \%$ of private health worker participants were found to have adequate knowledge in newborn care components. All others had only moderate to inadequate knowledge. Knowledge of the government health workers was significantly better than private health care staff $(P<0.005)$. Similarly, in a study done in Masindi, Uganda, it was found that $<50 \%$ of the health workers were found to be having adequate knowledge regarding the newborn care aspects [15].

It was noticed that the knowledge about newborn care is better among the government health workers compared to the private health worker in Karaikal. The reasons for this may be,

1. The higher mean years of working experience among government health workers compared to the private staff

2. More number of deliveries occurs only in the government sectors in Karaikal. Hence, less exposure to the newborn care may also be a reason for lower knowledge level among the private health-care staff.

\section{CONCLUSION}

The health workers are to provide health care and health information to pregnant and postnatal mothers. In this study, it was identified that the overall knowledge of the majority of the health-care workers, namely, nurses, midwives, and local house visitors who are employed in the government as well as the private health-care sectors of Karaikal is in the inadequate to a moderate level. Only $41.1 \%$ of government health workers and $22.3 \%$ of private health workers have an overall adequate knowledge in newborn care components. Although the knowledge was better among the government staff compared to the private staff, it was not found to be predominantly adequate. This indirectly conveys that newborn babies in the immediate postnatal period may not receive appropriate care and the mothers may not receive quality health advice which may result in complications or even death of the newborn.
This demands the conduction of education and training programs to improve the knowledge of the health workers of Karaikal. This may help in better newborn care and outcome in Karaikal. It will be good to check the knowledge of the health-care providers in all the parts of the country and improve wherever needed, to reduce neonatal mortality of the country and to reach the sustainable development goal by 2030 [16]

It can be assumed that this study will serve to convey the level of knowledge of health workers in Karaikal district towards newborn care as no such data available from this part of the country.

\section{LIMITATIONS OF THE STUDY}

It was only a questionnaire based study. With this, the practical skills of the health worker could not be assessed.

The knowledge and practice of doctors involved in supervising and providing neonatal care were not evaluated in this study.

\section{ACKNOWLEDGMENTS}

We would like to thank all the study participants who took part in the study and hospital in-charges for permitting to conduct the study with their employees in their premises.

\section{REFERENCES}

1. Lawn JE, Zupan J, Begkoyian G, Knippenberg R. Newborn survival. In: Jamison DT, Breman JG, Measham AR, Alleyne G, Claeson M, Evans DB, et al., editors. Disease Control Priorities in Developing Countries. $2^{\text {nd }}$ ed. Ch. 27. Washington, DC: The International Bank for Reconstruction and Development/The World Bank; Oxford University Press; 2006

2. Darmstadt GL, Bhutta ZA, Cousens S, Adam T, Walker N, de Bernis L; Lancet Neonatal Survival Steering Team. Evidence-based, costeffective interventions: How many newborn babies can we save? Lancet 2005;365(9463):977-88.

3. Martines J, Paul VK, Bhutta ZA, Koblinsky M, Soucat A, Walker $\mathrm{N}$, et al. Neonatal survival: A call for action. Lancet 2005;365(9465):1189-97.

4. Agrawal PK, Agrawal S, Ahmed S, Darmstadt GL, Williams EK, Rosen HE, et al. Effect of knowledge of community health workers on essential newborn health care: a study from rural India. Health Policy Plan 2012;27(2):115-26.

5. Sinha LN, Kau P, Gupta R, Dalpath S, Goyal V, Murhekar M. Newborn care practices and home-based postnatal newborn care programmeMewat, Haryana, India, 2013. Western Pac Surveill Response J 2013:5(3):1-8.

6. Osrin D, Tumbahangphe KM, Shrestha D, Mesko N, Shrestha BP, Manandhar MK, et al. Cross sectional, community based study of care of newborn infants in Nepal. BMJ 2002;325(7372):1063.

7. Moran AC, Choudhury N, Uz Zaman Khan N, Ahsan Karar Z, Wahed T, Faiz Rashid S, et al. Newborn care practices among slum dwellers in Dhaka, Bangladesh: A quantitativeand qualitative exploratory study. BMC Pregnancy Childbirth 2009;9:54.

8. Fikree FF, Ali TS, Durocher JM, Rahbar MH. Newborn care practices in low socioeconomic settlements of Karachi, Pakistan. Soc Sci Med 2005;60(5):911-21.

9. McCall EM, Alderdice F, Halliday HL, Jenkins JG, Vohra S. Interventions to prevent hypothermia at birth in preterm and/or low birthweight infants. Cochrane Database Syst Rev 2010;3:CD004210.

10. Rahi M, Taneja DK, Misra A, Mathur NB, Badhan S. Newborn care practices in an urban slum of Delhi. Indian J Med Sci 2006;60(12):506-13.

11. Al-Binali A. Knowledge, attitude and practice of breast-feeding among female health care workers in tertiary care hospitals. Med J Cairo Univ 2012;80(1):159-64.

12. Spear HJ. Nurses attitude, knowledge and belief related to the promotion of breastfeeding among women who bear children during adolescence. J Pediatr Nurs 2004;19(3):176-83.

13. Angadi MM, Jose AP, Udgiri R, Masali KA, Sorganvi V. A study of knowledge, attitude and practices on immunization of children 
in urban slums of Bijapur city, Karnataka, India. J Clin Diagn Res 2013;7(12):2803-6.

14. Awasthi S, Tuhina V, Monica A. Danger signs of neonatal illnesses: Perceptions of caregivers and health workers in Northern India. Bull World Health Organ 2006;84(10):819-26.

15. Ayiasi RM, Criel B, Orach CG, Nabiwemba E, Kolsteren P. Primary healthcare worker knowledge related to prenatal and immediate newborn care: A cross sectional study in Masindi, Uganda. BMC Health Serv Res 2014;14:65.

16. WHO. Children: Reducing Mortality. WHO. Available from: http:// www.who.int/mediacentre/factsheets/fs178/en. [Last cited on 2016 Mar 18]. 